Article

\title{
Synthesis and Broad-Spectrum Antiviral Activity of Some Novel Benzo-Heterocyclic Amine Compounds
}

\author{
Da-Jun Zhang ${ }^{\dagger}$, Wen-Fang Sun ${ }^{\dagger}$, Zhao-Jin Zhong ${ }^{\dagger}$, Rong-Mei Gao, Hong Yi, Yu-Huan Li, \\ Zong-Gen Peng * and Zhuo-Rong Li *
}

Institute of Medicinal Biotechnology, Chinese Academy of Medical Sciences \& Peking Union Medical College, Beijing 100050, China

$\dagger$ These authors contributed equally to this work.

* Authors to whom correspondence should be addressed; E-Mails: pumcpzg@126.com (Z.-G.P.); 1-Z-r@263.net (Z.-R.L.); Tel.: +86-10-6301-0984 (Z.-G.P.); +86-10-6302-7185 (Z.-R.L.); Fax: +86-10-6301-7302 (Z.-G.P. \& Z.-R.L.).

Received: 28 November 2013; in revised form: 8 January 2014 / Accepted: 9 January 2014 / Published: 15 January 2014

\begin{abstract}
A series of novel unsaturated five-membered benzo-heterocyclic amine derivatives were synthesized and assayed to determine their in vitro broad-spectrum antiviral activities. The biological results showed that most of our synthesized compounds exhibited potent broad-spectrum antiviral activity. Notably, compounds $3 \mathbf{f}\left(\mathrm{IC}_{50}=3.21-5.06 \mu \mathrm{M}\right)$ and $3 \mathbf{g}\left(\mathrm{IC}_{50}=0.71-34.87 \mu \mathrm{M}\right)$ showed potent activity towards both RNA viruses (influenza A, $\mathrm{HCV}$ and Cox B3 virus) and a DNA virus (HBV) at low micromolar concentrations. An SAR study showed that electron-withdrawing substituents located on the aromatic or heteroaromatic ring favored antiviral activity towards RNA viruses.
\end{abstract}

Keywords: unsaturated five-membered benzo-heterocyclic amines; broad-spectrum antiviral activity; DNA and RNA virus; SAR

\section{Introduction}

Viral infections pose a threat to virtually every organism in every domain of life. People over 65 years of age account for $90 \%$ of seasonal influenza-associated deaths, and influenza viruses with either high mortality or morbidity have heightened fears that the next influenza pandemic will occur 
soon [1,2]. The hepatitis $\mathrm{C}$ virus (HCV) is a significant bloodborne human pathogen that affects an estimated $3 \%$ of the world's population, $80 \%$ of whom progress to a chronic infectious state $[3,4]$. Currently, the standard of care (SOC) is a combination of pegylated interferon and ribavirin, but this regimen can cause severe side effects and poorly sustained viral response [5,6]. Although two protease inhibitors (Victrelis (boceprevir) and Incivek (telaprevir)) were approved by the USA FDA in 2011, both must be used in combination with ribavirin and pegylated interferon, and there is still an unmet need for the treatment of HCV infections. Hepatitis B virus (HBV) is a hepatotropic noncytopathic envelope virus that causes acute and chronic hepatitis. Although a vaccine has been developed, chronic hepatitis B (CHB) caused by hepatitis virus infection is still one of the most serious human viral infectious diseases worldwide. Worldwide more than 350 million people suffer from chronic HBV infections, many of whom subsequently develop more severe liver diseases such as cirrhosis and hepatocellular carcinoma (HCC) [7]. Coxsackie B viruses are single-strand RNA viruses, and infection with Cox B can cause fever, headache, chest pain and other problems. Cardiac infection with Cox B3 can result in acute myocarditis that is spontaneously resolved or chronic myocarditis with prolonged viral persistence [8]. Currently, there is no specific treatment or vaccine available for Coxsackie virus infections.

Most current antiviral drugs, including those in development, are direct-acting antiviral (DAA) molecules that specifically target viral proteins. These drugs are narrow in spectrum and are vulnerable to the rapid emergence of viral resistance [9]. The emergence of drug-resistant viruses, especially multidrug-resistant strains, represents a significant problem in current clinical practice that needs to be addressed and should be considered a high priority for new avenues of research [10,11]. To fulfill all of these requirements, novel classes of antivirals are needed [12]. Additionally, due to the high mutation rates that are particularly prevalent in RNA viruses, the lifetime of specific antiviral therapeutics is often severely limited. Broad spectrum antivirals would be one way of circumventing this problem [13]. Consequently, it is highly desirable to generate these types of drugs, and scientists are encouraged to research and develop novel broad spectrum antivirals.

Previously, we have reported a novel class of (5-oxazolyl)phenyl amines that act as potential inosine monophosphate dehydrogenase (IMPDH) inhibitors and exhibit broad-spectrum antiviral activities [14]. In continuance of our endeavor to search for novel antiviral agents with broad-spectrum antiviral activity, we designed a novel class of unsaturated five-membered benzo-heterocyclic derivatives using a ring transforming strategy that is based on our previously reported structures (Figure 1).

Figure 1. The chemical structure of the designed target compounds.

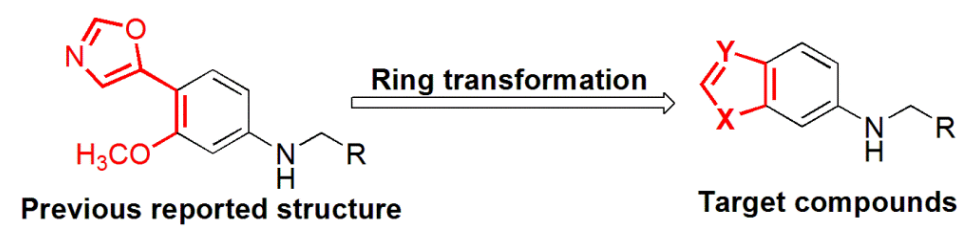

Moreover, the secondary amine derivatives showed potent antiviral activity against CoxB3, CoxB6 and HCV in our previous study. Therefore, the secondary amine derivatives were primarily synthesized in this work. Additionally, unsaturated five-membered benzo-heterocyclic scaffolds appear 
to be privileged structures, which were widely distributed among bioactive compounds and successful drugs [15-18]. Consequently, a novel class of unsaturated five-membered benzo-heterocyclesubstituted amines were synthesized and assayed for their broad spectrum antiviral activity in vitro, and their structure-activity relationships (SARs) were also investigated.

Scheme 1. Synthetic route to the target compounds $\mathbf{1 a}-\mathbf{4 b}$.

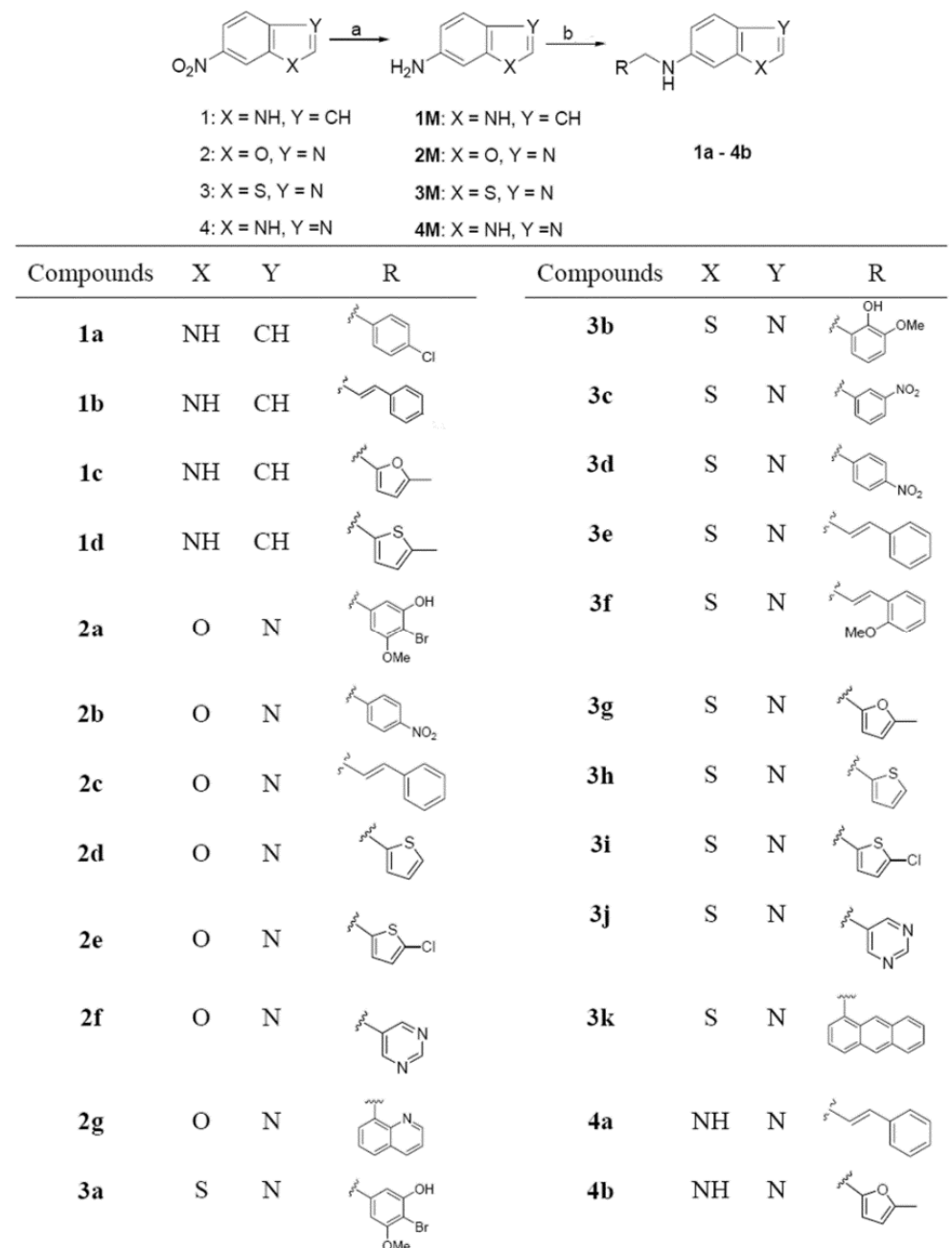

Reagents and conditions: (a) 10\% $\mathrm{Pd} / \mathrm{C}, \mathrm{H}_{2}(50 \mathrm{psi})$, EtOH, rt; and (b) various substituted aldehydes, EtOH, rt or reflux, $8 \mathrm{~h}$, then $\mathrm{NaBH}_{4}$, rt, $3 \mathrm{~h}$.

\section{Results and Discussion}

\subsection{Chemistry}

As depicted in Scheme 1, a series of novel benzo-heterocyclic amine derivatives containing the substituted or non-substituted aromatic/heteroaromatic rings were synthesized. The commercially available compounds 1-4 were chosen as starting materials and were reduced at 50 psi hydrogen over $\mathrm{Pd} / \mathrm{C}(10 \%)$ to produce the intermediate compounds $\mathbf{1 M}-\mathbf{4 M}$ which have been reported in the literature [19-22]. The target compounds were obtained via reductive amination with a yield of 50\%-65\%. Specifically, compounds $1 \mathbf{M}-\mathbf{4 M}$ were condensed with commercially available substituted aldehydes at room temperature or under reflux in ethanol to produce the intermediate Schiff bases, 
which were directly reduced without further purification in the presence of $\mathrm{NaBH}_{4}$ to generate the target compounds. In the case of compounds $\mathbf{4 a}$ and $\mathbf{4 b}$, which were insoluble in methylene chloride, ethyl acetate was used to extract the target products after workup. The chemical structures of the synthesized target compounds were all confirmed by ${ }^{1} \mathrm{H}-\mathrm{NMR},{ }^{13} \mathrm{C}-\mathrm{NMR}$ and HRMS.

\subsection{Biological Evaluation}

The synthesized target compounds were assayed for their broad spectrum antiviral activity towards influenza A, HBV, HCV and Cox B3 virus in vitro. Specifically, the activity against influenza A and Cox B3 was determined by the cytopathic effect (CPE) inhibitory assay, and oseltamivir and ribavirin (RBV) were used as positive controls, respectively. The inhibitory activities towards HBV and HCV were tested by real time PCR, and lamivudine (3TC) and teleprevir were used as positive controls, respectively. The results are summarized in Table 1.

In general, the majority of our synthesized compounds showed definitive broad spectrum activity against the viruses tested especially compounds $\mathbf{3 f}$ and $\mathbf{3 g}$, which exhibited potent activity towards the entire virus panel tested. $\mathrm{IC}_{50}$ values ranged from $0.71 \mu \mathrm{M}$ to $34.87 \mu \mathrm{M}$. Additionally, most of our synthesized compounds showed potent inhibitory activity towards Influenza A, HCV and Cox B3 virus simultaneously, including compounds $\mathbf{2 c , e , g , ~ 3 d - g , ~ 3 i ~ a n d ~ 4 a . ~ H o w e v e r , ~ o n l y ~} 3$ compounds (1a, $3 \mathbf{f}$ and 3g) showed inhibitory activity toward HBV. Based on these results, we concluded that our synthesized compounds were more sensitive to RNA viruses (Influenza A, HCV and Cox B3) when compared to a DNA virus (HBV).

\subsubsection{Anti-influenza Virus Activity}

The majority of the synthesized compounds exhibited potent antiviral activity towards influenza A/hanfang/359/95 virus. This was particularly true for compounds $\mathbf{1 d}, \mathbf{2 c}, \mathbf{e , g}, \mathbf{3 b}-\mathbf{f}, \mathbf{h}, \mathbf{i}$ and $\mathbf{4 a}$ because the $\mathrm{IC}_{50}$ values were superior or comparable to the positive control drugs (RBV and oseltamivir). Notably, compound 3d showed both potent inhibitory activity against influenza $\mathrm{A}\left(\mathrm{IC}_{50}=3.36 \mu \mathrm{M}\right)$ and the highest SI value (80.8) among the entire panel of synthesized compounds.

With regard to the structure-activity relationships, the activity of compounds $\mathbf{4 a}, \mathbf{b}$, and $\mathbf{3 e}, \mathbf{g}$ were superior to their indole and benzoxazole scaffold counterparts; we concluded that the benzimidazole and benzothiazole moieties favored anti-influenza activity. Replacement of the hydrogen at the 4 position of the thiophene ring ( $\mathbf{2} \mathbf{d}$ and $\mathbf{3 h}$ ) with a chloro group (2e and $\mathbf{3 i}$ ) increased the compounds' anti-influenza activity. The derivatives $\mathbf{2 b}$ and $\mathbf{3 d}$ containing a strong electron withdrawing group $\left(\mathrm{NO}_{2}\right)$ substituted at the para-position of the benzene ring also showed potent inhibitory activity. Migration of the $\mathrm{NO}_{2}$ group from the para-position (3d) to the meta-position (3c) slightly decreased the activity. Based on these results, we concluded that an electron withdrawing substituent on the aromatic or heteroaromatic ring favored anti-influenza A activity. 
Table 1. The antiviral activity and cytotoxicity of the compounds.

\begin{tabular}{|c|c|c|c|c|c|c|c|c|c|c|c|c|}
\hline \multirow{2}{*}{ NO. } & \multicolumn{3}{|c|}{ Influenza A/hanfang/359/95 } & \multicolumn{3}{|c|}{ Cox B3 } & \multicolumn{3}{|c|}{$\mathrm{HCV}$} & \multicolumn{3}{|c|}{ HBV } \\
\hline & $\mathrm{TC}_{50}(\mu \mathrm{M})$ & $\mathrm{IC}_{50}(\boldsymbol{\mu M})$ & SI & $\mathrm{TC}_{50}(\mu \mathrm{M})$ & $\mathrm{IC}_{50}(\mu \mathrm{M})$ & SI & $\mathrm{TC}_{50}(\mu \mathrm{M})$ & $\mathrm{IC}_{50}(\boldsymbol{\mu M})$ & SI & $\mathrm{TC}_{50}(\mu \mathrm{M})$ & $\mathrm{IC}_{50}(\mu \mathrm{M})$ & SI \\
\hline $1 \mathbf{a}$ & 3.35 & $>1.60$ & - & 8.34 & 4.79 & 1.7 & 15.88 & 1.40 & 11.3 & 8.02 & 1.44 & 5.6 \\
\hline 1b & 2.86 & $>1.65$ & - & 8.61 & 2.86 & 3.0 & NT & NT & NT & 3.21 & $>1.85$ & - \\
\hline $1 \mathrm{c}$ & 4.52 & $>0.66$ & - & 25.15 & 1.93 & 13.0 & 46.78 & 2.77 & 16.8 & 16.67 & $>5.56$ & - \\
\hline 1d & 26.50 & 11.84 & 2.2 & 66.10 & 1.69 & 39.1 & NT & NT & NT & 28.87 & $>16.67$ & - \\
\hline $2 a$ & 64.04 & $>10.60$ & - & 55.13 & 3.52 & 15.7 & 89.63 & 32.95 & 2.7 & 28.87 & $>16.67$ & - \\
\hline $2 b$ & 288.23 & 41.26 & 7.0 & 257.52 & 31.34 & 8.2 & $>200$ & $>66.67$ & $<3.0$ & 16.67 & $>5.56$ & - \\
\hline $2 c$ & 133.16 & 11.59 & 11.5 & 103.36 & 1.24 & 83.5 & 105.44 & 10.48 & 10.1 & 28.87 & $>16.67$ & - \\
\hline 2d & 434.24 & 34.43 & 11.6 & 100.35 & 9.29 & 10.8 & 136.53 & $>66.67$ & $<2.0$ & NT & NT & NT \\
\hline $2 e$ & 87.30 & 10.95 & 8.0 & 29.08 & 3.55 & 8.2 & 45.78 & 17.72 & 2.6 & 19.25 & $>11.11$ & - \\
\hline $2 f$ & 425.44 & $>98.32$ & - & 295.10 & 56.73 & 5.2 & NT & NT & NT & NT & NT & NT \\
\hline $2 \mathrm{~g}$ & 56.04 & 9.04 & 6.2 & 80.80 & 8.98 & 9.0 & 27.57 & 14.18 & 1.9 & NT & NT & NT \\
\hline $3 a$ & 21.08 & $>10.13$ & - & 21.08 & 10.13 & 2.1 & 108.82 & 48.99 & 2.2 & 28.87 & $>16.67$ & - \\
\hline $3 b$ & 55.95 & 10.02 & 5.6 & 67.23 & 5.66 & 11.9 & 126.59 & 38.01 & 3.3 & 57.74 & $>33.33$ & - \\
\hline $3 c$ & 45.01 & 12.47 & 3.6 & 112.45 & 7.23 & 15.6 & NT & NT & NT & NT & NT & NT \\
\hline 3d & 272.01 & 3.36 & 80.8 & 181.3 & 1.82 & 99.5 & 142.86 & 22.50 & 6.3 & 9.62 & $>5.56$ & - \\
\hline $3 e$ & 24.10 & 8.60 & 2.8 & 20.05 & 1.16 & 17.2 & 43.58 & 9.75 & 4.5 & 9.62 & $>5.56$ & - \\
\hline $3 f$ & 21.66 & 4.15 & 5.2 & 12.48 & 3.21 & 3.9 & 54.99 & 5.04 & 10.9 & 28.87 & 5.06 & 5.7 \\
\hline $3 g$ & 94.60 & 26.24 & 3.6 & 65.57 & 5.03 & 13.0 & 138.38 & 34.87 & 4.5 & 21.48 & 0.71 & 30.3 \\
\hline $3 \mathrm{~h}$ & 78.14 & 6.58 & 11.9 & 65.03 & 10.43 & 6.2 & 153.72 & 47.64 & 3.2 & NT & NT & NT \\
\hline $3 \mathbf{i}$ & 27.42 & 3.42 & 8.0 & 13.18 & 2.53 & 5.2 & 38.24 & 9.81 & 3.9 & 9.62 & $>5.56$ & - \\
\hline $3 \mathbf{j}$ & 826.44 & 213.80 & 3.9 & 826.44 & 52.98 & 15.6 & $>200$ & $>66.67$ & $<3.0$ & 28.87 & $>16.67$ & - \\
\hline $3 k$ & 1.73 & $>0.41$ & - & 2.09 & - & - & NT & NT & NT & NT & NT & NT \\
\hline $4 a$ & 14.84 & 4.93 & 3.0 & 25.75 & 6.38 & 4.0 & 79.04 & 5.51 & 14.3 & NT & NT & NT \\
\hline $4 b$ & 440.02 & 21.43 & 20.5 & 254.07 & 48.89 & 5.2 & $>200$ & 24.37 & $>8.2$ & $>50$ & $>50$ & - \\
\hline RBV & 4765.44 & 8.76 & 544.0 & 8205.90 & 2120.4 & 3.9 & NT & NT & NT & NT & NT & NT \\
\hline Oseltamivir & 4030.42 & 18.97 & 212.5 & NT & NT & NT & NT & NT & NT & NT & NT & NT \\
\hline 3TC & NT & NT & NT & NT & NT & NT & NT & NT & NT & $>100$ & 1.85 & $>54.1$ \\
\hline Telaprevir & NT & NT & NT & NT & NT & NT & 32.12 & 0.011 & 2920.0 & NT & NT & NT \\
\hline
\end{tabular}

$\mathrm{TC}_{50}, 50 \%$ cytotoxic concentration; $\mathrm{IC}_{50}, 50 \%$ inhibition concentration; SI, the selectivity index. NT means not tested. 
However, in the case of compound 3e, introduction of an electron-donating methoxyl group at the ortho-position of the benzene ring (3f) also increased antiviral activity, and this effect may not be due to its electron-donating property, but rather to the hydrogen bond-accepting properties of the methoxyl group. A complete loss in activity of compound $\mathbf{3 k}$ containing a bulky anthracene group may be due to steric hindrance.

\subsubsection{Anti Cox B3 Virus Activity}

As shown in Table 1, all of the synthesized compounds except 3k showed potent inhibitory activity towards Cox B3 at low micromolar concentrations, especially compounds $\mathbf{1 a}-\mathbf{d}, \mathbf{2 a}, \mathbf{c}, \mathbf{e}, \mathbf{3 d}-\mathbf{f}$ and $\mathbf{3 i}$, and the $\mathrm{IC}_{50}$ values were less than $5.0 \mu \mathrm{M}$. Notably, compounds $\mathbf{3 d}$ and $\mathbf{2 c}$ exhibited relatively high SI values (99.5 and 83.5, respectively). Based on the activity of compounds $\mathbf{1 b}, \mathbf{2 c}, \mathbf{3 e}$ and $4 \mathbf{a}$, we concluded that only the benzimidazole slightly disfavored anti-Cox B3 activity, and there was no significant difference among the other three scaffolds. Similar to the anti-influenza activity SAR, the derivatives containing electron-withdrawing groups (2e, 3d and 3i) showed relatively more potent activity. Substitution of an electron-donating methoxyl group (3f) for the hydrogen atom at the ortho- position of the benzene ring (3e) disfavored antiviral activity. Migration of the $\mathrm{NO}_{2}$ group from the para position (3d) to the meta-position (3c) also decreased its activity. Compound 3k showed no inhibitory activity, likely due to high steric hindrance.

\subsubsection{Anti HCV Activity}

As shown in Table 1, compounds 1a,c, 3e,f,i and 4a showed relatively potent anti-HCV activity with $\mathrm{IC}_{50}$ values of less than $10.0 \mu \mathrm{M}$. The $\mathrm{IC}_{50}$ values of all of the synthesized compounds were inferior to the positive control telaprevir, an NS3/4A protease inhibitor. However, the synthesized compounds exhibited less cytotoxicity when compared to telaprevir. Based on the activity of compounds $\mathbf{1 c}, \mathbf{3 g}$ and $\mathbf{4 b}$, the indole scaffold appeared to be the optimal fragment for anti-HCV activity. Given that compounds $\mathbf{2 e}$ and $\mathbf{3 i}$, which contain chloro groups at the thiophene ring, were more potent that their non-substituted counterparts, we concluded that the electron-withdrawing substituents were favorable for anti-HCV activity, a result that is consistent with the SAR of both antiinfluenza A and anti-Cox B3 activities. The most potent of the synthesized compounds was also the compound containing a chloro group at the para-position of the benzene ring (1a). The derivatives containing a styryl substituent (2c, 3e, 3f and 4a) also showed potent anti-HCV activity at low micromolar concentrations.

\subsubsection{Anti-HBV Activity}

HBV was less sensitive to the synthesized compounds compared to influenza A, Cox B3 and HCV virus, and only compounds $\mathbf{1 a}, \mathbf{3 f}$ and $\mathbf{3 g}$ showed definitive activity towards HBV. Among these, compounds $\mathbf{1 a}$ and $\mathbf{3 g}$ were more potent than the positive control 3TC, especially compound $\mathbf{3 g}$ which exhibited an $\mathrm{IC}_{50}$ value of less than $1.0 \mu \mathrm{M}(0.7 \mu \mathrm{M})$. Some simple SARs can be determined based on the biological results. Although compound $\mathbf{3 f}$ showed potent inhibitory activity towards HBV, compound 3e which lacks a methoxyl group at the ortho-position of the benzene ring did not exhibit 
any activity. Hence, the methoxyl group was indispensable for the anti-HBV activity of compound $\mathbf{3 f}$. Additionally, substitution of the indole (1c) or benzimidazole (4b) scaffold for the benzothiazole (3g) fragment led to a complete loss of antiviral activity.

\section{Experimental}

\subsection{General Information}

All solvents and reagents were of chemical or analytical grade. The progress of the reactions was monitored by TLC using solvent systems of different polarities. ${ }^{1} \mathrm{H}-\mathrm{NMR}$ and ${ }^{13} \mathrm{C}-\mathrm{NMR}$ spectra were recorded with a BrukerBioSpin GmbH (Rheinstetten, Germany) spectrometer at 400 or $500 \mathrm{MHz}$. Chemical shifts are reported in parts per million relative to a tetramethylsilane internal standard. Melting points were determined with an X6 microscope melting point apparatus and were not corrected. All mass spectra (MS, HRMS) were recorded on a LTQ-Orbitrap linear ion trap high-resolution mass spectrometer (ThermoFisher Scientific, San Jose, CA, USA).

\subsection{Chemistry}

\subsubsection{General procedure for the synthesis of $\mathbf{1 M}-\mathbf{4 M}$}

A mixture of compounds 1-4 (6.13 mmol) in ethanol $(30 \mathrm{~mL})$ was treated with $10 \% \mathrm{Pd} / \mathrm{C}(20 \mathrm{wt} . \%$ of 1-4) and subjected overnight to $50 \mathrm{psi}_{2}(\mathrm{~g})$ in a Parr hydrogenation apparatus. The reaction mixture was filtered and concentrated in vacuo. Pure products $\mathbf{1 M - 4 M}$ were obtained via flash chromatography by eluting with a gradient of $30 \%-40 \%$ EtOAc/hexanes.

1H-Indol-6-ylamine (1M). Gray solid, mp: 67-68 ${ }^{\circ} \mathrm{C}$; $90 \%$ yield; ${ }^{1} \mathrm{H}-\mathrm{NMR}\left(400 \mathrm{MHz}, \mathrm{CDCl}_{3}\right) \delta(\mathrm{ppm})$ : $7.87(1 \mathrm{H}, \mathrm{brs}), 7.40(1 \mathrm{H}, \mathrm{d}, J=8.4 \mathrm{~Hz}), 7.00(1 \mathrm{H}, \mathrm{m}), 6.67(1 \mathrm{H}, \mathrm{s}), 6.57\left(1 \mathrm{H}, \mathrm{dd}, J_{1}=8.4 \mathrm{~Hz}, J_{2}=2.0 \mathrm{~Hz}\right)$, $6.42(1 \mathrm{H}, \mathrm{m})$.

Benzooxazol-6-ylamine (2M). Yellow solid, mp: $86-87{ }^{\circ} \mathrm{C}$; $86 \%$ yield; ${ }^{1} \mathrm{H}-\mathrm{NMR}\left(400 \mathrm{MHz}\right.$, DMSO- $d_{6}$ ) $\delta(\mathrm{ppm}): 8.32(1 \mathrm{H}, \mathrm{s}), 7.39(1 \mathrm{H}, \mathrm{d}, J=8.8 \mathrm{~Hz}), 6.78(1 \mathrm{H}, \mathrm{d}, J=2.0 \mathrm{~Hz}), 6.64\left(1 \mathrm{H}, \mathrm{dd}, J_{1}=8.8 \mathrm{~Hz}\right.$, $\left.J_{2}=2.0 \mathrm{~Hz}\right), 5.36(1 \mathrm{H}, \mathrm{br})$.

Benzothiazol-6-ylamine (3M). Yellow solid, mp: 88-89 ${ }^{\circ} \mathrm{C}$; $88 \%$ yield; ${ }^{1} \mathrm{H}-\mathrm{NMR}\left(400 \mathrm{MHz}\right.$, DMSO- $d_{6}$ ) $\delta$ (ppm): $8.88(1 \mathrm{H}, \mathrm{s}), 7.71(1 \mathrm{H}, \mathrm{d}, J=8.4 \mathrm{~Hz}), 7.12(1 \mathrm{H}, \mathrm{d}, J=2.0 \mathrm{~Hz}), 6.81\left(1 \mathrm{H}, \mathrm{dd}, J_{1}=8.4 \mathrm{~Hz}\right.$, $\left.J_{2}=2.0 \mathrm{~Hz}\right), 5.40(2 \mathrm{H}, \mathrm{br})$.

3H-Benzoimidazol-5-ylamine (4M). Brown solid, mp: $121-122{ }^{\circ} \mathrm{C} ; 85 \%$ yield; ${ }^{1} \mathrm{H}-\mathrm{NMR}$ (400 MHz, DMSO- $\left.d_{6}\right) \delta(\mathrm{ppm}): 7.85(1 \mathrm{H}, \mathrm{s}), 7.24(1 \mathrm{H}, \mathrm{d}, J=8.4 \mathrm{~Hz}), 6.66(1 \mathrm{H}, \mathrm{s}), 6.50\left(1 \mathrm{H}, \mathrm{dd}, J_{1}=8.4 \mathrm{~Hz}\right.$, $\left.J_{2}=2.0 \mathrm{~Hz}\right), 4.80(2 \mathrm{H}, \mathrm{br})$.

\subsubsection{General procedure for the synthesis of $\mathbf{1 a}-\mathbf{1 e}, \mathbf{2 a}-\mathbf{2 g}, \mathbf{3 a}-\mathbf{3 f}$}

A mixture of the appropriate amine (1M-3M, $2 \mathrm{mmol})$ and the appropriate aldehyde $(2.2 \mathrm{mmol})$ in ethanol $(10 \mathrm{~mL})$ was stirred at room temperature for $8 \mathrm{~h}$ and $\mathrm{NaBH}_{4}(2.2 \mathrm{mmol})$ was subsequently 
added to the solution. After $3 \mathrm{~h}$, the reaction was completed. Water $(5 \mathrm{~mL})$ was then added to the solution and neutralized with aqueous $10 \% \mathrm{HCl} . \mathrm{CH}_{2} \mathrm{Cl}_{2}(40 \mathrm{~mL})$ was added to the solution, and the organic layer was separated, washed with saturated aqueous sodium chloride and subsequently dried over anhydrous $\mathrm{Na}_{2} \mathrm{SO}_{4}$. The solvent was removed under a vacuum. The residue was purified by chromatography on silica gel $($ EtOAc $/ n$-hexane $=1 / 3)$ to generate the corresponding compounds.

Characterization data for the title compounds:

(4-Chlorobenzyl)-(1H-indol-6-yl)-amine (1a). White solid, mp: $135-137{ }^{\circ} \mathrm{C}, 50 \%$ yield; ${ }^{1} \mathrm{H}-\mathrm{NMR}$ $\left(\mathrm{DMSO}-d_{6}, 500 \mathrm{MHz}\right) \delta(\mathrm{ppm}): 10.42(1 \mathrm{H}, \mathrm{s}), 7.39-7.31(4 \mathrm{H}, \mathrm{m}), 7.20-7.18(1 \mathrm{H}, \mathrm{m}), 6.93-6.92(1 \mathrm{H}$, m), 6.47-6.45 (1H, m), $6.35(1 \mathrm{H}, \mathrm{s}), 6.15(1 \mathrm{H}, \mathrm{s}), 5.93(1 \mathrm{H}, \mathrm{t}, J=6.0 \mathrm{~Hz}), 4.26(2 \mathrm{H}, \mathrm{d}, J=6.0 \mathrm{~Hz})$. ${ }^{13} \mathrm{C}-\mathrm{NMR}\left(125 \mathrm{MHz}, \mathrm{DMSO}-d_{6}\right) \delta$ (ppm): 144.6, 140.4, 137.8, 130.4, 129.4 (2C), 128.6 (2C), 122.2, 120.7, 119.9, 109.7, 101.3, 93.3, 47.1. HR-MS $\left(\mathrm{ESI}^{+}\right) \mathrm{m} / z: 257.0844[\mathrm{M}+\mathrm{H}]^{+}$, calcd for $\mathrm{C}_{15} \mathrm{H}_{14} \mathrm{ClN}_{2}^{+}, 257.0845$.

(E)-(1H-Indol-6-yl)-(3-phenylallyl)-amine (1b). White solid, mp: $130-132{ }^{\circ} \mathrm{C}, 53 \%$ yield; ${ }^{1} \mathrm{H}-\mathrm{NMR}$ $\left(500 \mathrm{MHz}, \mathrm{DMSO}-d_{6}\right) \delta(\mathrm{ppm}): 10.47(1 \mathrm{H}, \mathrm{s}), 7.40-7.39(2 \mathrm{H}, \mathrm{m}), 7.32-7.29(2 \mathrm{H}, \mathrm{m}), 7.22-7.19$ (2H, m), 6.96-6.95 $(1 \mathrm{H}, \mathrm{m}), 6.61(1 \mathrm{H}, \mathrm{d}, J=16.0 \mathrm{~Hz}), 6.51(1 \mathrm{H}, \mathrm{s}), 6.47\left(1 \mathrm{H}, \mathrm{dd}, J_{1}=8.5 \mathrm{~Hz}, J_{2}=2.0 \mathrm{~Hz}\right)$, 6.43-6.41 (1H, m), $6.17(1 \mathrm{H}, \mathrm{s}), 5.52(1 \mathrm{H}, \mathrm{t}, J=5.5 \mathrm{~Hz}), 3.86-3.84(2 \mathrm{H}, \mathrm{m}) .{ }^{13} \mathrm{C}-\mathrm{NMR}(125 \mathrm{MHz}$, DMSO- $\left.d_{6}\right) \delta(\mathrm{ppm}): 145.0,138.0,137.4,130.2,129.3,129.2$ (2C), 127.7, 126.5 (2C), 122.2, 120.6, 119.9, 109.7, 101.3, 93.2, 46.3. HR-MS $\left(\mathrm{ESI}^{+}\right) \mathrm{m} / \mathrm{z}: 249.1390[\mathrm{M}+\mathrm{H}]^{+}$, calcd for $\mathrm{C}_{17} \mathrm{H}_{17} \mathrm{~N}_{2}{ }^{+}, 249.1392$.

(1H-Indol-6-yl)-(5-methylfuran-2-ylmethyl)-amine (1c). White solid, mp: $100-102{ }^{\circ} \mathrm{C}, 50 \%$ yield; ${ }^{1} \mathrm{H}$ NMR (400 MHz, DMSO-d $)_{6} \delta(\mathrm{ppm}): 10.49(1 \mathrm{H}, \mathrm{s}), 7.19(1 \mathrm{H}, \mathrm{d}, J=8.4 \mathrm{~Hz}), 6.96-6.95$ (1H, m), 6.52 $(1 \mathrm{H}, \mathrm{s}), 6.46\left(1 \mathrm{H}, \mathrm{dd}, J_{1}=8.4 \mathrm{~Hz}, J_{2}=2.0 \mathrm{~Hz}\right), 6.17-6.16(1 \mathrm{H}, \mathrm{m}), 6.12(1 \mathrm{H}, \mathrm{d}, J=2.8 \mathrm{~Hz}), 5.95(1 \mathrm{H}$, $\mathrm{d}, J=2.0 \mathrm{~Hz}), 5.63(1 \mathrm{H}, \mathrm{t}, J=6.0 \mathrm{~Hz}), 4.15(2 \mathrm{H}, \mathrm{d}, J=6.0 \mathrm{~Hz}), 2.22(3 \mathrm{H}, \mathrm{s}) .{ }^{13} \mathrm{C}-\mathrm{NMR}(125 \mathrm{MHz}$ DMSO- $\left.d_{6}\right) \delta$ (ppm): 152.4, 150.7, 144.6, 137.9, 122.3, 120.6, 120.0, 109.6, 107.9, 106.7, 101.3, 93.3, 41.5, 13.8. HR-MS(ESI $\left.{ }^{+}\right) m / z: 227.1185[\mathrm{M}+\mathrm{H}]^{+}$, calcd for $\mathrm{C}_{14} \mathrm{H}_{15} \mathrm{~N}_{2} \mathrm{O}^{+}, 227.1184$.

(1H-Indol-6-yl)-(5-methylthiophen-2-ylmethyl)-amine (1d). White solid, mp: 89-91 ${ }^{\circ} \mathrm{C}, 50 \%$ yield; ${ }^{1} \mathrm{H}$ NMR (500 MHz, DMSO- $\left.d_{6}\right) \delta(\mathrm{ppm}): 10.47(1 \mathrm{H}, \mathrm{s}), 7.19(1 \mathrm{H}, \mathrm{d}, J=8.5 \mathrm{~Hz}), 6.96-6.95(1 \mathrm{H}, \mathrm{m}), 6.79$ $(1 \mathrm{H}, \mathrm{d}, J=3.0 \mathrm{~Hz}), 6.60(1 \mathrm{H}, \mathrm{d}, J=2.0 \mathrm{~Hz}), 6.51(1 \mathrm{H}, \mathrm{s}), 6.47\left(1 \mathrm{H}, \mathrm{dd}, J_{1}=8.5 \mathrm{~Hz}, J_{2}=2.0 \mathrm{~Hz}\right), 6.17$ $(1 \mathrm{H}, \mathrm{s}), 5.78(1 \mathrm{H}, \mathrm{t}, J=6.0 \mathrm{~Hz}), 4.33(2 \mathrm{H}, \mathrm{d}, J=6.0 \mathrm{~Hz}), 2.35(3 \mathrm{H}, \mathrm{s}) .{ }^{13} \mathrm{C}-\mathrm{NMR}(125 \mathrm{MHz}$ DMSO- $\left.d_{6}\right) \delta$ (ppm): 144.5, 143.1, 137.9, 137.8, 125.2, 124.6, 122.3, 120.6, 120.1, 109.8, 101.3, 93.6, 43.6, 15.5. HR-MS(ESI $\left.{ }^{+}\right) m / z: 243.0954[\mathrm{M}+\mathrm{H}]^{+}$, calcd for $\mathrm{C}_{14} \mathrm{H}_{15} \mathrm{~N}_{2} \mathrm{~S}^{+}, 243.0956$.

4-(Benzooxazol-6-ylaminomethyl)-2-bromo-6-methoxyphenol (2a). White solid, mp: $129-131{ }^{\circ} \mathrm{C}, 53 \%$ yield; ${ }^{1} \mathrm{H}-\mathrm{NMR}\left(400 \mathrm{MHz}, \mathrm{DMSO}-d_{6}\right) \delta(\mathrm{ppm}): 9.27(1 \mathrm{H}, \mathrm{s}), 8.33(1 \mathrm{H}, \mathrm{s}), 7.42(1 \mathrm{H}, \mathrm{d}, J=8.4 \mathrm{~Hz}), 7.08$ $(1 \mathrm{H}, \mathrm{s}), 7.01(1 \mathrm{H}, \mathrm{s}), 6.76(1 \mathrm{H}, \mathrm{d}, J=2.0 \mathrm{~Hz}), 6.72\left(1 \mathrm{H}, \mathrm{dd}, J_{1}=8.4 \mathrm{~Hz}, \mathrm{~J}_{2}=2.0 \mathrm{~Hz}\right), 6.51(1 \mathrm{H}, \mathrm{t}$, $J=6.0 \mathrm{~Hz}), 4.20(2 \mathrm{H}, \mathrm{d}, J=6.0 \mathrm{~Hz}), 3.80(3 \mathrm{H}, \mathrm{s}) .{ }^{13} \mathrm{C}-\mathrm{NMR}\left(125 \mathrm{MHz} \mathrm{DMSO}-d_{6}\right) \delta(\mathrm{ppm}): 151.6$, $151.4,148.9,148.2,142.9,132.2,130.5,123.2,120.3,112.4,111.1,109.7,92.9,56.6,46.6$. HR-MS(ESI ${ }^{+}$) $m / z: 349.0178[\mathrm{M}+\mathrm{H}]^{+}$, calcd for $\mathrm{C}_{15} \mathrm{H}_{14} \mathrm{~N}_{2} \mathrm{O}_{3} \mathrm{Br}^{+}, 349.0188$. 
Benzooxazol-6-yl-(4-nitrobenzyl)-amine (2b). Brown solid, mp: $154-156{ }^{\circ} \mathrm{C}, 65 \%$ yield; ${ }^{1} \mathrm{H}-\mathrm{NMR}$ $\left(400 \mathrm{MHz}, \mathrm{DMSO}-d_{6}\right) \delta(\mathrm{ppm}): 8.33(1 \mathrm{H}, \mathrm{s}), 8.19(2 \mathrm{H}, \mathrm{d}, J=8.8 \mathrm{~Hz}), 7.64(2 \mathrm{H}, \mathrm{d}, J=8.8 \mathrm{~Hz})$, $7.45-7.43(1 \mathrm{H}, \mathrm{d}, J=8.4 \mathrm{~Hz}), 6.80(1 \mathrm{H}, \mathrm{t}, J=6.0 \mathrm{~Hz}), 6.73-6.72(2 \mathrm{H}, \mathrm{m}), 4.49(2 \mathrm{H}, \mathrm{d}, J=6.0 \mathrm{~Hz})$. ${ }^{13} \mathrm{C}-\mathrm{NMR}$ (125 MHz DMSO- $\left.d_{6}\right) \delta(\mathrm{ppm}): 151.6,151.5,149.0,147.9,147.0,130.7,128.7$ (2C), 124.0 (2C), 120.5, 112.3, 93.0, 46.6. HR-MS $\left(\mathrm{ESI}^{+}\right) \mathrm{m} / \mathrm{z}: 270.0879[\mathrm{M}+\mathrm{H}]^{+}$, calcd for $\mathrm{C}_{14} \mathrm{H}_{12} \mathrm{~N}_{3} \mathrm{O}_{3}{ }^{+}, 270.0879$.

(E)-Benzooxazol-6-yl-(3-phenylallyl)-amine (2c). Light green solid, mp: $100-103{ }^{\circ} \mathrm{C}, 55 \%$ yield; ${ }^{1} \mathrm{H}$ NMR (400 MHz, DMSO- $\left.d_{6}\right) \delta(\mathrm{ppm}): 8.34(1 \mathrm{H}, \mathrm{s}), 7.45-7.40(3 \mathrm{H}, \mathrm{m}), 7.33-7.29(2 \mathrm{H}, \mathrm{m}), 7.24-7.20$ $(1 \mathrm{H}, \mathrm{m}), 6.82(1 \mathrm{H}, \mathrm{d}, J=2.0 \mathrm{~Hz}), 6.74\left(1 \mathrm{H}, \mathrm{dd}, J_{1}=8.8 \mathrm{~Hz}, J_{2}=2.0 \mathrm{~Hz}\right), 6.63(1 \mathrm{H}, \mathrm{d}, J=16.0 \mathrm{~Hz})$, $6.38(1 \mathrm{H}, \mathrm{m}), 6.27(1 \mathrm{H}, \mathrm{t}, J=5.6 \mathrm{~Hz}), 3.91-3.87(2 \mathrm{H}, \mathrm{m}) .{ }^{13} \mathrm{C}-\mathrm{NMR}\left(125 \mathrm{MHz}\right.$ DMSO- $\left.d_{6}\right) \delta(\mathrm{ppm})$ : $151.7,151.3,148.5,137.2,130.8,129.1$ (2C), 128.9, 128.1, 127.8, 126.6 (2C), 120.2, 112.3, 92.7, 45.7. HR-MS $\left(\mathrm{ESI}^{+}\right) \mathrm{m} / z: 251.1176[\mathrm{M}+\mathrm{H}]^{+}$, calcd for $\mathrm{C}_{16} \mathrm{H}_{15} \mathrm{~N}_{2} \mathrm{O}^{+}, 251.1184$.

Benzooxazol-6-yl-thiophen-2-ylmethylamine (2d). Light green solid, mp: $62-64{ }^{\circ} \mathrm{C}$, $62 \%$ yield; ${ }^{1} \mathrm{H}-\mathrm{NMR}\left(400 \mathrm{MHz}, \mathrm{DMSO}-d_{6}\right) \delta(\mathrm{ppm}): 8.35(1 \mathrm{H}, \mathrm{s}), 7.43(1 \mathrm{H}, \mathrm{d}, J=8.8 \mathrm{~Hz}), 7.37(1 \mathrm{H}, \mathrm{d}$, $J=5.2 \mathrm{~Hz}), 7.09(1 \mathrm{H}, \mathrm{d}, J=3.2 \mathrm{~Hz}), 6.98-6.95(1 \mathrm{H}, \mathrm{m}), 6.85(1 \mathrm{H}, \mathrm{d}, J=2.0 \mathrm{~Hz}), 6.75(1 \mathrm{H}, \mathrm{dd}$, $\left.J_{1}=8.8 \mathrm{~Hz}, J_{2}=2.0 \mathrm{~Hz}\right), 6.59(1 \mathrm{H}, \mathrm{t}, J=6.0 \mathrm{~Hz}), 4.50(2 \mathrm{H}, \mathrm{d}, J=6.0 \mathrm{~Hz}) .{ }^{13} \mathrm{C}-\mathrm{NMR}(125 \mathrm{MHz}$ DMSO- $\left.d_{6}\right): \delta$ (ppm): 151.6, 151.5, 148.0, 144.2, 130.6, 127.3, 125.6, 125.1, 120.3, 112.5, 93.1, 42.7. HR-MS (ESI $\left.{ }^{+}\right) m / z: 231.0582[\mathrm{M}+\mathrm{H}]^{+}$, calcd for $\mathrm{C}_{12} \mathrm{H}_{11} \mathrm{~N}_{2} \mathrm{OS}^{+}, 231.0592$.

Benzooxazol-6-yl-(5-chlorothiophen-2-ylmethyl)-amine (2e). Light green solid, mp: $100-102{ }^{\circ} \mathrm{C}, 58 \%$ yield; ${ }^{1} \mathrm{H}-\mathrm{NMR}\left(400 \mathrm{MHz}, \mathrm{DMSO}-d_{6}\right) \delta(\mathrm{ppm}): 8.36(1 \mathrm{H}, \mathrm{s}), 7.45(1 \mathrm{H}, \mathrm{d}, J=8.8 \mathrm{~Hz}), 6.97-6.95(2 \mathrm{H}$, $\mathrm{m}), 6.86(1 \mathrm{H}, \mathrm{d}, J=2.0 \mathrm{~Hz}), 6.73\left(1 \mathrm{H}, \mathrm{dd}, J_{1}=8.8 \mathrm{~Hz}, J_{2}=2.0 \mathrm{~Hz}\right), 6.63(1 \mathrm{H}, \mathrm{t}, J=6.0 \mathrm{~Hz}), 4.45(2 \mathrm{H}$, $J=6.0 \mathrm{~Hz}) .{ }^{13} \mathrm{C}-\mathrm{NMR}\left(125 \mathrm{MHz}\right.$ DMSO- $\left.d_{6}\right) \delta(\mathrm{ppm}): 151.7,151.5,147.7,144.2,130.9,126.9,126.7$, 125.3, 120.1, 112.6, 93.3, 42.9. HR-MS $\left(\mathrm{ESI}^{+}\right) \mathrm{m} / z: 265.0210[\mathrm{M}+\mathrm{H}]^{+}$, calcd for $\mathrm{C}_{12} \mathrm{H}_{10} \mathrm{~N}_{2} \mathrm{OSCl}^{+}$, 265.0202 .

Benzooxazol-6-yl-pyrimidin-5-ylmethyl-amine (2f). Gray solid, mp: $175-177{ }^{\circ} \mathrm{C}, 51 \%$ yield; ${ }^{1} \mathrm{H}-\mathrm{NMR}$ $\left(500 \mathrm{MHz}, \mathrm{DMSO}-d_{6}\right) \delta(\mathrm{ppm}): 9.06(1 \mathrm{H}, \mathrm{s}), 8.81(2 \mathrm{H}, \mathrm{s}), 8.35(1 \mathrm{H}, \mathrm{s}), 7.45(1 \mathrm{H}, \mathrm{d}, J=8.5 \mathrm{~Hz}), 6.85$ $(1 \mathrm{H}, \mathrm{d}, J=1.5 \mathrm{~Hz}), 6.74\left(1 \mathrm{H}, \mathrm{dd}, J_{1}=8.5 \mathrm{~Hz}, J_{2}=1.5 \mathrm{~Hz}\right), 6.61(1 \mathrm{H}, \mathrm{t}, J=6.0 \mathrm{~Hz}), 4.38(2 \mathrm{H}, \mathrm{d}$, $J=6.0 \mathrm{~Hz}) .{ }^{13} \mathrm{C}-\mathrm{NMR}\left(125 \mathrm{MHz}\right.$ DMSO- $\left.d_{6}\right) \delta$ (ppm): 157.6, 156.8 (2C), 156.0, 151.7, 151.6, 133.5, 130.8, 120.5, 112.5, 93.2, 42.6. HR-MS (ESI $\left.{ }^{+}\right) \mathrm{m} / z: 227.0934[\mathrm{M}+\mathrm{H}]^{+}$, calcd for $\mathrm{C}_{12} \mathrm{H}_{11} \mathrm{~N}_{4} \mathrm{O}^{+}, 227.0933$.

Benzooxazol-6-yl-quinolin-8-ylmethylamine (2g). Gray solid, mp: $98-100{ }^{\circ} \mathrm{C}, 63 \%$ yield; ${ }^{1} \mathrm{H}-\mathrm{NMR}$ $\left(500 \mathrm{MHz}, \mathrm{DMSO}-d_{6}\right) \delta(\mathrm{ppm}): 8.99-8.98(1 \mathrm{H}, \mathrm{m}), 8.39(1 \mathrm{H}, \mathrm{d}, J=8.5 \mathrm{~Hz}), 8.29(1 \mathrm{H}, \mathrm{s}), 7.87(1 \mathrm{H}, \mathrm{d}$, $J=8.0 \mathrm{~Hz}), 7.73(1 \mathrm{H}, \mathrm{d}, J=7.0 \mathrm{~Hz}), 7.60-7.57(1 \mathrm{H}, \mathrm{m}), 7.56-7.52(1 \mathrm{H}, \mathrm{m}), 7.42-7.40(1 \mathrm{H}, \mathrm{m})$, $6.75-6.74(2 \mathrm{H}, \mathrm{m}), 6.62(1 \mathrm{H}, \mathrm{t}, J=6.0 \mathrm{~Hz}), 4.95(2 \mathrm{H}, \mathrm{d}, J=6.0 \mathrm{~Hz}) .{ }^{13} \mathrm{C}-\mathrm{NMR}\left(125 \mathrm{MHz}\right.$ DMSO- $\left.d_{6}\right)$ $\delta$ (ppm): 151.7, 151.3, 150.2, 148.6, 146.4, 137.4, 137.0, 130.4, 128.4, 127.9, 127.4, 126.8, 121.9, 120.3, 112.2, 92.7, 42.4. HR-MS (ESI $\left.{ }^{+}\right) \mathrm{m} / z: 276.1125[\mathrm{M}+\mathrm{H}]^{+}$, calcd for $\mathrm{C}_{17} \mathrm{H}_{14} \mathrm{~N}_{3} \mathrm{O}^{+}, 276.1137$.

4-(Benzothiazol-6-ylaminomethyl)-2-bromo-6-methoxyphenol (3a). White solid, mp: $193-195{ }^{\circ} \mathrm{C}, 54 \%$ yield; ${ }^{1} \mathrm{H}-\mathrm{NMR}\left(400 \mathrm{MHz}, \mathrm{DMSO}-d_{6}\right) \delta(\mathrm{ppm}): 9.27(1 \mathrm{H}, \mathrm{s}), 8.89(1 \mathrm{H}, \mathrm{s}), 7.54(1 \mathrm{H}, \mathrm{d}, J=8.4 \mathrm{~Hz}), 7.10$ $(1 \mathrm{H}, \mathrm{d}, J=2.4 \mathrm{~Hz}), 7.08(1 \mathrm{H}, \mathrm{s}), 7.01(1 \mathrm{H}, \mathrm{d}, J=2.4 \mathrm{~Hz}), 6.89\left(1 \mathrm{H}, \mathrm{dd}, J_{1}=8.4 \mathrm{~Hz}, J_{2}=2.4 \mathrm{~Hz}\right), 6.53$ 
$(1 \mathrm{H}, \mathrm{d}, J=6.0 \mathrm{~Hz}), 4.22(2 \mathrm{H}, \mathrm{d}, J=6.0 \mathrm{~Hz}), 3.80(3 \mathrm{H}, \mathrm{s}) .{ }^{13} \mathrm{C}-\mathrm{NMR}\left(125 \mathrm{MHz}\right.$ DMSO- $\left.d_{6}\right) \delta(\mathrm{ppm}):$ 149.9, 148.9, 147.5, 145.4, 143.0, 135.9, 132.2, 123.5, 123.2, 115.0, 111.1, 109.7, 102.0, 56.6, 46.5. HR-MS $\left(\mathrm{ESI}^{+}\right) \mathrm{m} / z: 364.9953[\mathrm{M}+\mathrm{H}]^{+}$, calcd for $\mathrm{C}_{15} \mathrm{H}_{14} \mathrm{~N}_{2} \mathrm{O}_{2} \mathrm{SBr}^{+}, 364.9959$.

2-(Benzothiazol-6-ylaminomethyl)-6-methoxyphenol (3b). Pale yellow solid, mp: 206-208 ${ }^{\circ} \mathrm{C}, 59 \%$ yield; ${ }^{1} \mathrm{H}-\mathrm{NMR}\left(400 \mathrm{MHz}, \mathrm{DMSO}-d_{6}\right) \delta(\mathrm{ppm}): 8.87(1 \mathrm{H}, \mathrm{s}), 8.73(1 \mathrm{H}, \mathrm{s}), 7.72(1 \mathrm{H}, \mathrm{d}, J=8.8 \mathrm{~Hz})$, $7.05(1 \mathrm{H}, \mathrm{d}, J=2.0 \mathrm{~Hz}), 6.88\left(1 \mathrm{H}, \mathrm{dd}, J_{1}=8.8 \mathrm{~Hz}, J_{2}=2.0 \mathrm{~Hz}\right), 6.85(1 \mathrm{H}, \mathrm{s}), 6.83(1 \mathrm{H}, \mathrm{s}), 6.72-6.68$ $(1 \mathrm{H}, \mathrm{m}), 6.38(1 \mathrm{H}, \mathrm{t}, J=6.0 \mathrm{~Hz}), 4.26(2 \mathrm{H}, \mathrm{d}, J=6.0 \mathrm{~Hz}), 3.80(3 \mathrm{H}, \mathrm{s}) .{ }^{13} \mathrm{C}-\mathrm{NMR}(125 \mathrm{MHz}$ DMSO- $\left.d_{6}\right) \delta(\mathrm{ppm}): 149.6,147.9,147.8,145.2,144.4,135.9,126.4,123.5,120.7,119.1,114.8,110.9$, 101.5, 56.3, 41.9. HR-MS (ESI $\left.{ }^{+}\right) m / z: 287.0851[\mathrm{M}+\mathrm{H}]^{+}$, calcd for $\mathrm{C}_{15} \mathrm{H}_{15} \mathrm{~N}_{2} \mathrm{O}_{2} \mathrm{~S}^{+}, 287.0854$.

Benzothiazol-6-yl-(3-nitrobenzyl)-amine (3c). Yellow solid, mp: $126-128{ }^{\circ} \mathrm{C}, 54 \%$ yield; ${ }^{1} \mathrm{H}-\mathrm{NMR}$ $\left(500 \mathrm{MHz}, \mathrm{DMSO}-d_{6}\right) \delta(\mathrm{ppm}): 8.89(1 \mathrm{H}, \mathrm{s}), 8.24(1 \mathrm{H}, \mathrm{s}), 8.09\left(1 \mathrm{H}, \mathrm{dd}, J_{1}=8.0 \mathrm{~Hz}, J_{2}=1.5 \mathrm{~Hz}\right), 7.84$ $(1 \mathrm{H}, \mathrm{d}, J=8.0 \mathrm{~Hz}), 7.74(1 \mathrm{H}, \mathrm{d}, J=9.0 \mathrm{~Hz}), 7.64-7.61(1 \mathrm{H}, \mathrm{m}), 7.11(1 \mathrm{H}, \mathrm{d}, J=2.5 \mathrm{~Hz}), 6.90(1 \mathrm{H}$, $\left.\mathrm{dd}, J_{1}=9.0 \mathrm{~Hz}, J_{2}=2.5 \mathrm{~Hz}\right), 6.80(1 \mathrm{H}, \mathrm{t}, J=6.0 \mathrm{~Hz}), 4.49(2 \mathrm{H}, \mathrm{d}, J=6.0 \mathrm{~Hz}) .{ }^{13} \mathrm{C}-\mathrm{NMR}(125 \mathrm{MHz}$ DMSO- $\left.d_{6}\right) \delta$ (ppm): 150.2, 148.4, 147.1, 145.6, 143.2, 136.0, 134.4, 130.3, 123.7, 122.3, 122.2, 115.0, 102.1, 46.2. HR-MS $\left(\mathrm{ESI}^{+}\right) \mathrm{m} / z: 286.0661[\mathrm{M}+\mathrm{H}]^{+}$, calcd for $\mathrm{C}_{14} \mathrm{H}_{12} \mathrm{~N}_{3} \mathrm{O}_{2} \mathrm{~S}^{+}, 286.0650$.

Benzothiazol-6-yl-(4-nitrobenzyl)-amine (3d). Brown solid, mp: $157-159{ }^{\circ} \mathrm{C}, 57 \%$ yield; ${ }^{1} \mathrm{H}-\mathrm{NMR}$ $\left(400 \mathrm{MHz}, \mathrm{DMSO}-d_{6}\right) \delta(\mathrm{ppm}): 8.90(1 \mathrm{H}, \mathrm{s}), 8.20(2 \mathrm{H}, \mathrm{d}, J=8.4 \mathrm{~Hz}), 7.75(1 \mathrm{H}, \mathrm{d}, J=8.8 \mathrm{~Hz}), 7.64$ $(2 \mathrm{H}, \mathrm{d}, J=8.4 \mathrm{~Hz}), 7.07(1 \mathrm{H}, \mathrm{d}, J=2.4 \mathrm{~Hz}), 6.89\left(1 \mathrm{H}, \mathrm{dd}, J_{1}=8.8 \mathrm{~Hz}, J_{2}=2.4 \mathrm{~Hz}\right), 6.84-6.80(1 \mathrm{H}, \mathrm{t}$, $J=6.4 \mathrm{~Hz}), 4.50(2 \mathrm{H}, \mathrm{d}, J=6.4 \mathrm{~Hz}) .{ }^{13} \mathrm{C}-\mathrm{NMR}\left(125 \mathrm{MHz}\right.$ DMSO- $\left.d_{6}\right) \delta$ (ppm): 150.2, 149.0, 147.2, 147.0, 145.5, 136.0, 128.7 (2C), 124.0 (2C), 123.7, 114.9, 102.0, 46.5. HR-MS (ESI $\left.{ }^{+}\right) \mathrm{m} / \mathrm{z}: 286.0652$ $[\mathrm{M}+\mathrm{H}]^{+}$, calcd for $\mathrm{C}_{14} \mathrm{H}_{12} \mathrm{~N}_{3} \mathrm{O}_{2} \mathrm{~S}^{+}, 286.0650$.

(E)-benzothiazol-6-yl-(3-phenyl-allyl)-amine (3e). Brown solid, mp: $99-101{ }^{\circ} \mathrm{C}, 57 \%$ yield; ${ }^{1} \mathrm{H}-\mathrm{NMR}$ $\left(400 \mathrm{MHz}, \mathrm{DMSO}-d_{6}\right) \delta(\mathrm{ppm}): 8.89(1 \mathrm{H}, \mathrm{s}), 7.75(1 \mathrm{H}, \mathrm{d}, J=8.8 \mathrm{~Hz}), 7.41(2 \mathrm{H}, \mathrm{d}, J=7.6 \mathrm{~Hz})$, 7.33-7.29 (2H,m), 7.24-7.20 (1H, m), $7.16(1 \mathrm{H}, \mathrm{d}, J=2.4 \mathrm{~Hz}), 6.90\left(1 \mathrm{H}, \mathrm{dd}, J_{1}=8.8 \mathrm{~Hz}, J_{2}=2.0 \mathrm{~Hz}\right)$, $6.63(1 \mathrm{H}, \mathrm{d}, J=16.0 \mathrm{~Hz}), 6.43-6.36(1 \mathrm{H}, \mathrm{m}), 6.30(1 \mathrm{H}, \mathrm{t}, J=5.2 \mathrm{~Hz}), 2.50(2 \mathrm{H}, \mathrm{t}, J=5.2 \mathrm{~Hz})$. ${ }^{13} \mathrm{C}-\mathrm{NMR}\left(125 \mathrm{MHz}\right.$ DMSO- $\left.d_{6}\right) \delta$ (ppm): 149.8, 147.7, 145.3, 137.2, 136.0, 130.8, 129.1(2C), 128.1, $127.8,126.6(2 \mathrm{C}), 123.5,115.0,101.7,45.5$. HR-MS $\left(\mathrm{ESI}^{+}\right) \mathrm{m} / \mathrm{z}: 267.0956[\mathrm{M}+\mathrm{H}]^{+}$, calcd for $\mathrm{C}_{16} \mathrm{H}_{15} \mathrm{~N}_{2} \mathrm{~S}^{+}, 267.0956$.

(E)-benzothiazol-6-yl-[3-(2-methoxy-phenyl)-allyl]-amine (3f). Pale yellow solid, mp: 107-109 ${ }^{\circ} \mathrm{C}$, $60 \%$ yield; ${ }^{1} \mathrm{H}-\mathrm{NMR}\left(400 \mathrm{MHz}, \mathrm{DMSO}-d_{6}\right) \delta(\mathrm{ppm}): 8.89(1 \mathrm{H}, \mathrm{s}), 7.75(1 \mathrm{H}, \mathrm{d}, J=8.8 \mathrm{~Hz}), 7.46(1 \mathrm{H}$, $\left.\mathrm{dd}, J_{1}=7.6 \mathrm{~Hz}, J_{2}=1.6 \mathrm{~Hz}\right), 7.24-7.20(1 \mathrm{H}, \mathrm{m}), 7.15(1 \mathrm{H}, \mathrm{d}, J=2.4 \mathrm{~Hz}), 6.98(1 \mathrm{H}, \mathrm{d}, J=8.8 \mathrm{~Hz})$, 6.92-6.95 (3H, m), 6.38-6.28 (2H, m), 3.92-3.90 (2H, m), 3.77 (3H, s). ${ }^{13} \mathrm{C}-\mathrm{NMR}\left(125 \mathrm{MHz}\right.$ DMSO- $\left.d_{6}\right)$ $\delta$ (ppm): 156.7, 149.7, 147.8, 145.2, 136.0, 129.1, 128.5, 127.0, 125.7, 125.6, 123.5, 121.0, 115.0, 111.8, 101.7, 55.8, 46.0. HR-MS (ESI $\left.{ }^{+}\right) m / z: 297.1060[\mathrm{M}+\mathrm{H}]^{+}$, calcd for $\mathrm{C}_{17} \mathrm{H}_{17} \mathrm{~N}_{2} \mathrm{OS}^{+}, 297.1062$.

Benzothiazol-6-yl-(5-methylfuran-2-ylmethyl)-amine (3g). Pale yellow solid, mp: $52-54{ }^{\circ} \mathrm{C}, 63 \%$ yield; ${ }^{1} \mathrm{H}-\mathrm{NMR}$ (400 MHz, DMSO- $d_{6}$ ) $\delta(\mathrm{ppm}): 8.90(1 \mathrm{H}, \mathrm{s}), 7.74(1 \mathrm{H}, \mathrm{d}, J=8.8 \mathrm{~Hz}), 7.20(1 \mathrm{H}, \mathrm{d}, J=2.0 \mathrm{~Hz})$, $6.91\left(1 \mathrm{H}, \mathrm{dd}, J_{1}=8.8 \mathrm{~Hz}, J_{2}=2.0 \mathrm{~Hz}\right), 6.41(1 \mathrm{H}, \mathrm{t}, J=6.0 \mathrm{~Hz}), 6.21(1 \mathrm{H}, \mathrm{d}, J=2.8 \mathrm{~Hz}), 5.98-5.97$ 
$(1 \mathrm{H}, J=2.8 \mathrm{~Hz}), 4.23(2 \mathrm{H}, \mathrm{d}, J=6.0 \mathrm{~Hz}), 2.22(3 \mathrm{H}, \mathrm{s}) .{ }^{13} \mathrm{C}-\mathrm{NMR}\left(125 \mathrm{MHz}\right.$ DMSO-$\left.d_{6}\right) \delta(\mathrm{ppm})$ : 151.4, 151.1, 149.6, 147.3, 145.4, 135.0, 123.5, 115.0, 108.2, 106.7, 101.9, 40.5, 13.8. HR-MS (ESI $\left.{ }^{+}\right)$ $m / z: 245.0742[\mathrm{M}+\mathrm{H}]^{+}$, calcd for $\mathrm{C}_{13} \mathrm{H}_{13} \mathrm{~N}_{2} \mathrm{OS}^{+}, 245.0749$.

Benzothiazol-6-yl-thiophen-2-ylmethylamine (3h). Light brown solid, mp: $148-150{ }^{\circ} \mathrm{C}$, $61 \%$ yield; ${ }^{1} \mathrm{H}-\mathrm{NMR}\left(400 \mathrm{MHz}, \mathrm{DMSO}-d_{6}\right) \delta(\mathrm{ppm}): 8.91(1 \mathrm{H}, \mathrm{s}), 7.75(1 \mathrm{H}, \mathrm{d}, J=8.8 \mathrm{~Hz}), 7.37(1 \mathrm{H}, \mathrm{d}, J=4.8$ $\mathrm{Hz}), 7.19(1 \mathrm{H}, \mathrm{d}, J=2.0 \mathrm{~Hz}), 7.09(1 \mathrm{H}, \mathrm{d}, J=3.2 \mathrm{~Hz}), 6.98-6.95(1 \mathrm{H}, \mathrm{m}), 6.91\left(1 \mathrm{H}, \mathrm{dd}, J_{1}=8.8 \mathrm{~Hz}\right.$, $\left.J_{2}=2.0 \mathrm{~Hz}\right), 6.62(1 \mathrm{H}, \mathrm{t}, J=6.0 \mathrm{~Hz}), 4.52(2 \mathrm{H}, \mathrm{d}, J=6.0 \mathrm{~Hz}) \cdot{ }^{13} \mathrm{C}-\mathrm{NMR}\left(125 \mathrm{MHz}\right.$ DMSO- $\left.d_{6}\right) \delta$ (ppm): 150.1, 147.2, 145.6, 144.2, 135.9, 127.3, 125.6, 125.2, 123.5, 115.1, 102.2, 42.5. HR-MS $\left(\mathrm{ESI}^{+}\right) \mathrm{m} / \mathrm{z}: 247.0362[\mathrm{M}+\mathrm{H}]^{+}$, calcd for $\mathrm{C}_{12} \mathrm{H}_{11} \mathrm{~N}_{2} \mathrm{~S}_{2}{ }^{+}, 247.0364$.

Benzothiazol-6-yl-(5-chlorothiophen-2-ylmethyl)-amine (3i). Brown solid, mp: $104-106{ }^{\circ} \mathrm{C}, 62 \%$ yield; ${ }^{1} \mathrm{H}-\mathrm{NMR}\left(400 \mathrm{MHz}, \mathrm{DMSO}-d_{6}\right) \delta(\mathrm{ppm}): 8.93(1 \mathrm{H}, \mathrm{s}), 7.76(1 \mathrm{H}, \mathrm{d}, J=8.8 \mathrm{~Hz}), 7.19(1 \mathrm{H}, \mathrm{d}$, $J=2.0 \mathrm{~Hz}), 6.97-6.95(2 \mathrm{H}, \mathrm{m}), 6.90\left(1 \mathrm{H}, \mathrm{dd}, J_{1}=8.8 \mathrm{~Hz}, J_{2}=2.0 \mathrm{~Hz}\right), 6.67(1 \mathrm{H}, \mathrm{t}, J=6.0 \mathrm{~Hz})$, $4.46(2 \mathrm{H}, \mathrm{d}, J=6.0 \mathrm{~Hz}) .{ }^{13} \mathrm{C}-\mathrm{NMR}\left(125 \mathrm{MHz} \mathrm{DMSO}-d_{6}\right) \delta(\mathrm{ppm}): 150.4,146.9,145.7,144.2,135.9$, 126.9, 126.7, 125.3, 123.6, 115.1, 102.4, 42.8. HR-MS $\left(\mathrm{ESI}^{+}\right) \mathrm{m} / z: 280.9980[\mathrm{M}+\mathrm{H}]^{+}$, calcd for $\mathrm{C}_{12} \mathrm{H}_{10} \mathrm{~N}_{2} \mathrm{~S}_{2} \mathrm{Cl}^{+}, 280.9974$.

Benzothiazol-6-yl-pyrimidin-5-ylmethyl-amine (3j). Pale yellow solid, mp: $127-129{ }^{\circ} \mathrm{C}, 51 \%$ yield; ${ }^{1} \mathrm{H}-\mathrm{NMR}\left(500 \mathrm{MHz}, \mathrm{DMSO}-d_{6}\right) \delta(\mathrm{ppm}): 9.06(1 \mathrm{H}, \mathrm{s}), 8.91(1 \mathrm{H}, \mathrm{s}), 8.81(2 \mathrm{H}, \mathrm{s}), 7.75(1 \mathrm{H}, \mathrm{d}$, $J=9.0 \mathrm{~Hz}), 7.19(1 \mathrm{H}, \mathrm{d}, J=2.5 \mathrm{~Hz}), 6.90\left(1 \mathrm{H}, \mathrm{dd}, J_{1}=9.0 \mathrm{~Hz}, J_{2}=2.5 \mathrm{~Hz}\right), 6.64(1 \mathrm{H}, \mathrm{t}, J=6.0 \mathrm{~Hz})$, $4.39(2 \mathrm{H}, \mathrm{d}, J=6.0 \mathrm{~Hz}) .{ }^{13} \mathrm{C}-\mathrm{NMR}\left(125 \mathrm{MHz} \mathrm{DMSO}-d_{6}\right) \delta(\mathrm{ppm}): 157.6,156.8(2 \mathrm{C}), 150.4,147.0$, 145.7, 136.0, 133.5, 123.7, 115.1, 102.2, 42.5. HR-MS $\left(\mathrm{ESI}^{+}\right) \mathrm{m} / \mathrm{z}: 243.0710[\mathrm{M}+\mathrm{H}]^{+}$, calcd for $\mathrm{C}_{12} \mathrm{H}_{11} \mathrm{~N}_{4} \mathrm{~S}^{+}, 243.0704$.

Anthracen-9-ylmethyl-benzothiazol-6-yl-amine (3k). Yellow solid, mp: $174-176{ }^{\circ} \mathrm{C}$, 64\% yield; ${ }^{1} \mathrm{H}-\mathrm{NMR}\left(400 \mathrm{MHz}, \mathrm{DMSO}-d_{6}\right) \delta(\mathrm{ppm}): 8.96(1 \mathrm{H}, \mathrm{s}), 8.66(1 \mathrm{H}, \mathrm{s}), 8.30(2 \mathrm{H}, \mathrm{d}, J=8.4 \mathrm{~Hz}), 8.15-8.13$ $(2 \mathrm{H}, \mathrm{m}), 7.79(1 \mathrm{H}, \mathrm{d}, J=8.8 \mathrm{~Hz}), 7.60-7.52(5 \mathrm{H}, \mathrm{m}), 7.01\left(1 \mathrm{H}, \mathrm{dd}, J_{1}=8.8 \mathrm{~Hz}, J_{2}=2.0 \mathrm{~Hz}\right), 6.32(1 \mathrm{H}$, $\mathrm{t}, J=4.0 \mathrm{~Hz}), 5.14(2 \mathrm{H}, \mathrm{d}, J=4.0 \mathrm{~Hz}) .{ }^{13} \mathrm{C}-\mathrm{NMR}\left(125 \mathrm{MHz}\right.$ DMSO- $\left.d_{6}\right) \delta(\mathrm{ppm}): 149.8,148.2,145.4$, 136.1, 131.6 (2C), 130.7 (2C), 130.2, 129.4 (2C), 127.8, 126.8 (2C), 125.7 (2C), 125.0 (2C), 123.5, 115.1, 101.4, 40.6. HR-MS (ESI $\left.{ }^{+}\right) m / z: 341.1104[\mathrm{M}+\mathrm{H}]^{+}$, calcd for $\mathrm{C}_{22} \mathrm{H}_{17} \mathrm{~N}_{2} \mathrm{~S}^{+}, 341.1112$.

Preparation of (E)-(3H-Benzoimidazol-5-yl)-(3-phenyl-allyl)-amine (4a). A mixture of compound 4M $(2 \mathrm{mmol})$ and trans-3-phenylpropenal $(2.2 \mathrm{mmol})$ in ethanol $(15 \mathrm{~mL})$ was stirred at room temperature for $8 \mathrm{~h}$, and $\mathrm{NaBH}_{4}(2.2 \mathrm{mmol})$ was then added to the solution which was mixed overnight. The solvent concentration was halved by diluting it with water and was extracted by ethyl acetate $(3 \times 15 \mathrm{~mL})$. The combined organic layers were dried over $\mathrm{Na}_{2} \mathrm{SO}_{4}$ and evaporated. The residue was purified by flash chromatography on silica using a $\mathrm{CH}_{2} \mathrm{Cl}_{2} / \mathrm{MeOH}$ gradient and the compound $4 \mathrm{a}$ was generated in the form of a yellow solid, mp: $140-142{ }^{\circ} \mathrm{C}, 52 \%$ yield; ${ }^{1} \mathrm{H}-\mathrm{NMR}\left(400 \mathrm{MHz}, \mathrm{DMSO}-d_{6}\right) \delta$ (ppm): 7.90 $(1 \mathrm{H}, \mathrm{s}), 7.45-7.29(6 \mathrm{H}, \mathrm{m}), 7.23-7.20(1 \mathrm{H}, \mathrm{m}), 6.65-6.61(3 \mathrm{H}, \mathrm{m}), 6.42(1 \mathrm{H}, \mathrm{t}, J=5.2 \mathrm{~Hz}), 3.87(2 \mathrm{H}$, $\mathrm{d}, J=5.2 \mathrm{~Hz}) .{ }^{13} \mathrm{C}-\mathrm{NMR}\left(125 \mathrm{MHz}\right.$ DMSO- $\left.d_{6}\right) \delta$ (ppm): 145.7, 139.9, 137.3, 130.4, 129.4, 129.1 (2C), 129.0, 128.0, 127.7, 126.5 (2C), 117.5, 111.5, 94.7, 46.3. HR-MS $\left(\mathrm{ESI}^{+}\right) \mathrm{m} / z: 250.1341[\mathrm{M}+\mathrm{H}]^{+}$, calcd for $\mathrm{C}_{16} \mathrm{H}_{16} \mathrm{~N}_{3}^{+}, 250.1344$. 
(3H-Benzoimidazol-5-yl)-(5-methyl-furan-2-ylmethyl)-amine (4b). Compound $\mathbf{4 b}$ was synthesized using a method similar to that of $4 \mathrm{a}$ and was isolated as a brown solid. mp: $75-77{ }^{\circ} \mathrm{C}$; $55 \%$ yield; ${ }^{1} \mathrm{H}-\mathrm{NMR}$ (400 MHz; DMSO- $\left.d_{6}\right) \delta$ (ppm): $8.07(1 \mathrm{H} ; \mathrm{s}) ; 7.35(1 \mathrm{H} ; \mathrm{d} ; J=8.8 \mathrm{~Hz}) ; 6.71-6.69(2 \mathrm{H}, \mathrm{m})$; $6.18(1 \mathrm{H}, \mathrm{d} ; J=2.8 \mathrm{~Hz}) ; 6.00-5.99(1 \mathrm{H}, \mathrm{m}) ; 4.22(2 \mathrm{H} ; \mathrm{s}) ; 2.25(3 \mathrm{H} ; \mathrm{s}) .{ }^{13} \mathrm{C}-\mathrm{NMR}\left(125 \mathrm{MHz}\right.$ DMSO- $\left.d_{6}\right) \delta$ (ppm): 152.0; 150.9; 146.8; 139.8; 136.9; 131.5; 117.0; 112.1; 108.1; 106.7; 94.8; 41.3; 13.7. HR-MS $\left(\mathrm{ESI}^{+}\right) \mathrm{m} / z: 228.1135[\mathrm{M}+\mathrm{H}]^{+}$; calcd for $\mathrm{C}_{13} \mathrm{H}_{14} \mathrm{~N}_{3} \mathrm{O}^{+} ; 228.1137$.

\subsection{Antiviral Assays}

Madin-Darby Canine Kidney (MDCK) cells, African green monkey kidney cells (Vero) and Coxsackie viruses (Cox B3 Nancy strain) were all purchased from ATCC. 2.2.15 cells, an HBV-transfected human HepG2 cell line [23], were kindly provided by Y.C. Cheng (Yale Medical School, New Haven, CT, USA). Huh7.5 human liver cells (kindly provided by Vertex Pharmaceuticals, Boston, MA) were cultured in Dulbecco's Modified Eagle's Medium (DMEM, Invitrogen, Carlsbad, CA, USA) supplemented with 10\% inactivated fetal bovine serum (Invitrogen) and 1\% penicillin-streptomycin (Invitrogen). Influenza A strains were all obtained from the Institute of Virology, Chinese Academy of Preventive Medicine. The plasmid pFL-J6/JFH/JC1 containing the full-length chimeric HCV cDNA was kindly provided by Vertex Pharmaceuticals (Boston, MA, USA).

\subsubsection{Cytotoxicity Assay}

The cytotoxicity of the compounds in MDCK, Vero and HepG2.2.15 cells was monitored via cytopathic effect (CPE) assays. The MDCK and Vero cells $\left(2.5 \times 10^{4} /\right.$ well $)$ were plated in a 96-well plate. Following a $24 \mathrm{~h}$ hold period, the monolayer of cells was incubated in the presence of various concentrations of the test compounds. Following $48 \mathrm{~h}$ of culture at $37{ }^{\circ} \mathrm{C}$ under a $5 \% \mathrm{CO}_{2}$ atmosphere in an incubator, the cells were monitored by CPE. The $\mathrm{TC}_{50}$ value was calculated using Reed \& Muench analysis.

The HepG2.2.15 cells $\left(2.5 \times 10^{4} /\right.$ well $)$ were plated in a 96-well plate, and after a $48 \mathrm{~h}$ incubation, the supernatant was replaced by fresh culture medium containing the test compounds. Cells were cultured for 3 days at $37{ }^{\circ} \mathrm{C}$ in a $5 \% \mathrm{CO}_{2}$ atmosphere in an incubator, and the medium was replaced with fresh medium containing the test compounds for an additional 3 days. The cells were subsequently monitored by $\mathrm{CPE}$ and the $\mathrm{TC}_{50}$ value was calculated using Reed and Muench analysis.

The Huh7.5 cells $\left(1 \times 10^{4}\right.$ cells/well $)$ were plated in 96-well plates. Six hours later the culture media was replaced with fresh medium containing the test compounds at various concentrations. Cytotoxicity was evaluated with the 3-(4,5-dimethylthiazol-2-yl)-2,5-diphenyltetrazolium bromide (MTT) assay after $96 \mathrm{~h}$. The $50 \%$ cytotoxicity concentration $\left(\mathrm{TC}_{50}\right)$ was calculated with Reed and Muench methods.

\subsubsection{Anti-Influenza Assays}

Confluent MDCK cells grown in 96-well microplates were infected with influenza $\mathrm{A}$ at a median tissue culture infective dose $\mathrm{TCID}_{50}$ of 100 . After $2 \mathrm{~h}$ of viral adsorption at $37^{\circ} \mathrm{C}$, the monolayers were washed with PBS and incubated at $37{ }^{\circ} \mathrm{C}$ in the maintenance medium with or without different concentrations of test compounds. Viral cytopathic effect (CPE) was measured when the viral control 
group reached a value of 4 and the antiviral activities of the synthesized compounds were determined by Reed and Muench analyses.

\subsubsection{Anti-HBV Assays}

The anti-HBV activities of test compounds and a positive control drug were tested in HepG2.2.15 cells. The HepG2.2.15 cells were cultured in 96-well plates and treated with the test compounds at $37{ }^{\circ} \mathrm{C}$ for 3 days. The medium was removed, and fresh medium containing the test compounds was added for an additional 3 days. The cells were harvested and intracellular DNA was extracted. The inhibition of viral DNA replication in treated cells versus untreated cells was determined by real time PCR.

\subsubsection{Anti-HCV Assays}

Huh7.5 cells were seeded at a density of $3 \times 10^{4}$ cells $/ \mathrm{cm}^{2}$. After $24 \mathrm{~h}$ of incubation, the cells were infected with an HCV viral stock (approximately 45 IU per cell) and simultaneously treated with Telaprevir, the test compounds, or the solvent control. The culture medium was removed $96 \mathrm{~h}$ after inoculation, and the total intracellular RNA and total intracellular proteins were extracted with a Qiagen Kit according to the manufacturer's instructions. Intracellular HCV RNA was quantified using a one-step real time RT-PCR kit (Invitrogen). Cytotoxicity was tested by the MTT assay, and $\mathrm{IC}_{50}$ values were calculated by the Reed and Muench methods.

\subsubsection{Anti-Coxsackie B3 Activity Assays}

Confluent Vero cells grown in 96-well plates were infected with a median tissue culture infective dose of 100 (100TCID50) Cox B3 viruses. After $1 \mathrm{~h}$ of viral adsorption at $37^{\circ} \mathrm{C}$, the monolayers were washed with phosphate buffered saline (PBS) and incubated at $37{ }^{\circ} \mathrm{C}$ in the maintenance medium (MEM plus 2\% fetal bovine serum (FBS)) with or without different concentrations of test compounds. Viral cytopathic effect (CPE) was measured when the viral control group reached a level of 4 and the antiviral activity of test compounds was determined by the Reed and Muench analyses.

\section{Conclusions}

A total of 24 novel benzo-heterocyclic amine derivatives were designed, synthesized and screened for their antiviral activities towards influenza A, HBV, HCV and Cox B3 in this study. In general, the target compounds were more effective against RNA viruses (influenza A, HCV and Cox B3) than the DNA virus (HBV), and the majority of the synthesized compounds simultaneously exhibited potent activity against the influenza A, HCV and Cox B3 viruses. Additionally, a similar trend was observed among the SARs of the synthesized compounds towards the RNA virus. Different substituents on the aromatic ring had certain effects on the activity. For example, an electron-withdrawing substituent on the aromatic or heteroaromatic ring favored antiviral activity. Notably, compounds $\mathbf{3 f}$ and $\mathbf{3 g}$ showed potent antiviral activity towards the entire virus panel tested at low micromolar concentrations, especially compound $\mathbf{3 f}$ which was active against the entire virus panel tested with an $\mathrm{IC}_{50}$ value of approximately $5.0 \mu \mathrm{M}$. The detailed structure optimization of compound $\mathbf{3 f}$ and the study of the mechanisms of action of these compounds are ongoing in our laboratory. 


\section{Acknowledgments}

This work was supported by the National Natural Science Foundation of China (81273439) and the National Mega-project for Innovative Drugs (2012ZX09301002-001-024-02).

\section{Conflicts of Interest}

The authors declare no conflict of interest.

\section{References}

1. Zhang, X.; Qi, X.; Zhang, Q.; Zeng, X.; Shi, Z.; Jin, Q.; Zhan, F.; Xu, Y.; Liu, Z.; Feng, Z.; et al. Human 4F5 single-chain Fv antibody recognizing a conserved HA1 epitope has broad neutralizing potency against H5N1 influenza A viruses of different clades. Antivir. Res. 2013, 99, 91-99.

2. Metersky, M.L.; Masterton, R.G.; Lode, H.; File, T.M., Jr.; Babinchak, T. Epidemiology, microbiology, and treatment considerations for bacterial pneumonia complicating influenza. Int. J. Infect. Dis. 2012, 16, 321-331.

3. Choo, Q.L.; Kuo, G.; Weiner, A.J.; Overby, L.R.; Bradley, D.W.; Houghton, M. Isolation of a cDNA clone derived from a blood-bornc non-A, non-B viral hepatitis genomc. Science 1989, 244 , 359-362.

4. Alter, M.J. Epidemiology of hepatitis C virus infection. World J. Gastroenterol. 2007, 13, 2436-2441.

5. Kesel, A.J. Broad-spectrum antiviral activity including human immunodeficiency and hepatitis $\mathrm{C}$ viruses mediated by a novel retinoid thiosemicarbazone derivative. Eur. J. Med. Chem. 2011, 46, 1656-1664.

6. Lawitz, E.; Sulkowski, M.; Jacobson, I.; Kraft, W.K.; Maliakkal, B.; Al-lbrahim, M.; Gordon, S.C.; Kwo, P.; Rockstroh, J.K.; Panorchan, P.; et al. Characterization of vaniprevir, a hepatitis $\mathrm{C}$ virus NS3/4A protease inhibitor, in patients with HCV genotype 1 infection: Safety, antiviral activity, resistance, and pharmacokinetics. Antivir. Res. 2013, 99, 214-220.

7. Huang, C.C.; Kuo, T.M.; Yeh, C.T.; Hu, C.P.; Chen, Y.L.; Tsai, Y.L.; Chen, M.L.; Chou, Y.C.; Chang, C. One single nucleotide difference alters the differential expression of spliced RNAs between HBV genotypes A and D. Virus Res. 2013, 174, 18-26.

8. Pinkert, S.; Klingel, K.; Lindig, V.; Dörner, A.; Zeichhardt, H.; Spiller, O.B.; Fechner, H. Virus-host coevolution in a persistently coxsackievirus B3-infected cardiomyocyte cell line. J. Virol. 2011, 85, 13409-13419.

9. Bedard, K.M.; Wang, M.L.; Proll, S.C.; Loo, Y.M.; Katze, M.G.; Gale, M., Jr.; Ladonato, S.P. Isoflavone agonists of IRF-3 dependent signaling have antiviral activity against RNA viruses. J. Virol. 2012, 86, 7334-7344.

10. Richman, D.D. Antiviral drug resistance. Antivir. Res. 2006, 71, 117-121.

11. Colman, P.M. New antivirals and drug resistance. Annu. Rev. Biochem. 2009, 78, 95-118. 
12. Krepstakies, M.; Luciflra, J.; Naqel, C.H.; Zeisel, M.B.; Holstermann, B.; Hohenberq, H.; Kowalski, I.; Gutsmann, T.; Baumert, T.F.; Brandenburg, K.; et al. A new class of synthetic peptide inhibitors blocks attachment and entry of human pathogenic viruses. J. Infect. Dis. 2012, 205, 1654-1664.

13. ElSawy, K.M.; Twarock, R.; Verma, C.S.; Caves, L.S. Peptide inhibitors of viral assembly: A novel route to broad-spectrum antivirals. J. Chem. Inform. Model. 2012, 52, 770-776.

14. Zhong, Z.J.; Zhang, D.J.; Peng, Z.G.; Li, Y.H.; Shan, G.Z.; Zuo, L.M.; Wu, L.T.; Li, S.Y.; Gao, R.M.; Li, Z.R. Synthesis and antiviral activity of a novel class of (5-oxazolyl)phenyl amines. Eur. J. Med. Chem. 2013, 69, 32-43.

15. Wang, T.; Zhang, Z.; Wallace, O.B.; Deshpande, M.; Fang, H.; Yang, Z.; Zadjura, L.M.; Tweedie, D.L.; Huang, S.; Zhao, F.; et al. Discovery of 4-benzoyl-1-[(4-methoxy-1Hpyrrolo[2,3-b]pyridin-3-yl)oxoacetyl]-2- (R)-methylpiperazine (BMS-378806): a novel HIV-1 attachment inhibitor that interferes with CD4-gp120 interactions. J. Med. Chem. 2003, 46, 4236-4239.

16. Garuti, L.; Roberti, M.; de Clercq, E. Synthesis and antiviral/antiproliferative activity of some N-sulphonylbenzimidazoles. Bioorg. Med. Chem. Lett. 2002, 12, 2707-2710.

17. Cheng, J.; Xie, J.; Luo, X. Synthesis and antiviral activity against Coxsackie virus B3 of some novel benzimidazole derivatives. Bioorg. Med. Chem. Lett. 2005, 15, 267-269.

18. De Sá Alves, F.R.; Barreiro, E.J.; Fraga, C.A. From nature to drug discovery: The indole scaffold as a 'privileged structure'. Mini Rev. Med. Chem. 2009, 9, 782-793.

19. Yee, Y.K.; Bernstein, P.R.; Adams, E.J.; Brown, F.J.; Cronk, L.A.; Hebbel, K.C.; Vacek, E.P.; Krell, R.D.; Snyder, D.W. A novel series of selective leukotriene antagonists: Exploration and optimization of the acidic region in 1,6-disubstituted indoles and indazoles. J. Med. Chem. 1990, $33,2437-2451$.

20. Jagadeesh, R.V.; Wienhöfer, G.; Westerhaus, F.A.; Surkus, A.E.; Pohl, M.M.; Junqe, H.; Junqe, K.; Beller, M. Efficient and highly selective iron-catalyzed reduction of nitroarenes. Chem. Commun. 2011, 47, 10972-10974.

21. Hrobárik, P.; Hrobáriková, V.; Sigmundová, I.; Zahradník, P.; Fakis, M.; Polyzos, I.; Persephonis, P. Benzothiazoles with tunable electron-withdrawing strength and reverse polarity: A route to triphenylamine-based chromophores with enhanced two-photon absorption. J. Org. Chem. 2011, 76, 8726-8736.

22. Rahaim, R.J., Jr.; Maleczka, R.E., Jr. Pd-catalyzed silicon hydride reductions of aromatic and aliphatic nitro groups. Org. Lett. 2005, 7, 5087-5090.

23. Sells, M.A.; Chen, M.L.; Acs, G. Production of hepatitis B virus particles in Hep G2 cells transfected with cloned Hepatitis B virus DNA. Proc. Natl. Acad. Sci. USA. 1987, 84, 1005-1009.

Sample Availability: Samples of the entire panel of target compounds are available from the authors.

(C) 2014 by the authors; licensee MDPI, Basel, Switzerland. This article is an open access article distributed under the terms and conditions of the Creative Commons Attribution license (http://creativecommons.org/licenses/by/3.0/). 